\title{
Structurally decryptable complexes - a new taxonomic unit in cosmo-geological research
}

\author{
Isomiddin Togaev ${ }^{1}$, Anvarbek Nurkhodjaev ${ }^{2}$, Shamshodbek Akmalov ${ }^{3, *}$ \\ ${ }^{1}$ National University of Uzbekistan named after Mirzo Ulugbek, Tashkent, Uzbekistan \\ ${ }^{2}$ Institute for Advanced Studies and Retraining of Geological Sector Workers of the State Committee \\ for Geology of the Republic of Uzbekistan, Uzbekistan \\ ${ }^{3}$ Tashkent Institute of Irrigation and Agricultural Mechanization Engineers, 100000, M. Ulugbek str., \\ Tashkent, Uzbekistan
}

\begin{abstract}
The article presents the results of studies on the use of remote sensing data for the selection of geological structures based on structurally interpretable complexes. In addition, modern digital materials of satellite images of the Earth's surface, obtained from different satellite systems were used. The purpose of this research is the creation of a new generation of cosmogeological maps-remote fundamentals of the study area based on the integrated use of satellite imagery with geological and geophysical data. The structurally-decrypted complexes (SDC) were identified on the remote bases cosmogeological maps compiled using digital satellite images on base all Republic of Uzbekistan. Denoting tectonic disturbances and ring structures, as well as summarizing cosmogical and geological information, it is possible to distinguish predicted areas; one can solve various current geological problems by analyzing satellite imagery channels. One of the new scientific and thematic solutions of the research is the autonomous isolation of intrusive, sedimentary-volcanogenic and sedimentary structurally-deciphered complexes in combination with the structural and geodynamic features of the region, which helps to identify elements that are not distinguished by other methods.
\end{abstract}

\section{Introduction}

The territory of the Republic of Uzbekistan is characterized by a high degree of geological and geophysical studies. The use of Earth remote sensing (ERS) materials and geological and geophysical data significantly supplement geological information about the area of research.

At present, cosmogeological methods (or methods of remote sensing of the Earth) are one of the priority areas of research.

The remote base is presented in the form of digital photographs and graphic materials. Materials, as a rule, are presented in the form of spectrozonal images of the earth's surface and are presented in the cartographic projection and geodetic system of the topographic base, on which the distance base is based. The interpretation part of the remote basis is the

\footnotetext{
*Corresponding author: shamshodbekjon@mail.ru
} 
decryption scheme, created on the basis of cosmogeological and field materials. With the advent of the possibility of obtaining digital photographs of the Earth, a new era began in the use of satellite imagery (SI) materials to create remote sensing. The remote basis, as a new type of cartographic products, is an independent document of regional geological research, reflecting a new level of data organization, involving previously unknown or unused factors combining data arising from traditional research methods on a single basis in the process of mapping large areas. The current state of exploration is at the stage of aggregating all available data by research area and requires analysis of materials based on modern software products and GIS technologies.

The use of modern high-tech technologies and materials of high-resolution remote sensing, of various scales, should provide an increase in the objectivity and reliability of geological information, and contribute to solving geological problems.

In modern conditions, when regional geological survey works and searches are carried out in various regions, cosmogeological research and satellite imagery materials are becoming operational additional data to identify promising positions of endogenous mineralization.

Using space methods in geological research, geological problems can be solved promptly, which affects the increase in the efficiency of exploration work.

\section{Methods}

The methods of geological interpretation of remote sensing materials are determined by the goals and objectives of the thematic work, the scope of the study and the landscape of the study area. $[5,6]$. One of the priority areas of comprehensive geological research at the present stage is cosmogeological research in various mining regions. With the advent of digital images, the work performed on the basis of remote sensing materials was of a completely different nature and is widely used at regional and local levels of geological research. Naturally, along with this, the possibilities of using remote sensing materials expanded much and the methodology of geological interpretation was significantly improved.

O.M.Borisov, A.K. Glukh, V.N. Bryukhanov, F.A. Usmanov, Sh.E. Ergashev, Ya.G. Katz, F. were engaged in decoding and interpretation of aerospace data and Earth remote sensing data. G. Ryabukhin, A.K. Nurkhodzhaev, M.Kh. Khodzhibekov, M.N. Tkhai, G.M. Potorzhinsky, A.A. Abdurakhmanov, A.R. Asadov, A.R. Avezov and others. Geological isolation structures justified by specific criteria developed by the authors themselves. We conducted similar studies based on the isolation of structurally decryptable complexes (SDK).

The remote base is a modern digital information product created based on the materials of remote sensing of the Earth. It is an independent basis of regional geological research, reflecting a new level of data organization, involving large areas, previously unknown or unused factors arising from non-traditional research methods in the mapping process.

The advantage of the remote base is that it explains the geological structure of the area from a new perspective and helps to identify elements that are not distinguished by other methods. The main geological units identified in the analysis of Earth remote sensing materials are linear and ring structures, structurally decryptable complexes that make up the framework of the endogenous structure, are the basis for compiling geological, cosmogeological and other maps of a new generation [1].

In this work, based on satellite imagery, interpretation, generalized structurallydecryptable complexes of the territory of the Republic of Uzbekistan are highlighted. In addition, in this article some results of cosmogeological studies of the territory of the South Nuratau mountains are used. Creating a remote basis includes several basic methods, such 
as comparing and comparing objects within the same image and their logical interpretation $[3,4,5,12]$. Structurally decryptable complexes (SDK) are the qualitative features of objects of geological nature that are decrypted on Earth remote sensing materials, which contribute to the allocation of geological structures by the nature of the phototone, pattern, and the saturation of the spectral brightness of the image.

One of the new scientific and thematic solutions of the research is the autonomous isolation of intrusive, sedimentary-volcanogenic and sedimentary structurally-deciphered complexes in combination with the structural and geodynamic features of the region, which helps to identify elements that are not distinguished by other methods.

\section{Results and discussions}

The experience of large- and medium-scale studies in individual mining regions - showed that the revealed new tectonic structures (tectonic shielding, wedge-shaped, ring, linear structures, etc.) made us analyze the geodynamic situation of the constituent structures of individual regions in a new way (Fig. 1).

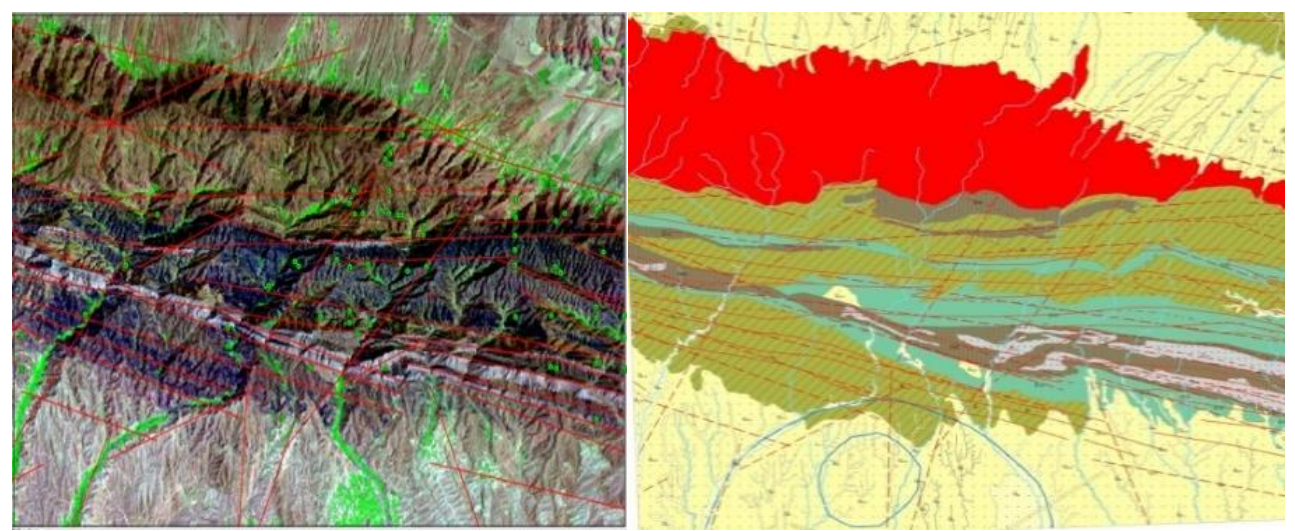

Fig. 1. Space image (A) and the results of creating a remote base (B) the territory of the South Nuratau mountains.

It should be noted that recently, during geodynamic and metallogenic studies, much attention has been paid to the so-called "mixtite" complexes.

Mikstites are chaotic complexes of tectonic (melange), gravitational (olistostromes) and mixed rock origin (Mirkamalov R.Kh. et al. 2014).

Deciphering them using satellite imagery, it was possible to identify all varieties by the nature and structure of the picture, the hypsometric levels of the mountain structures and the composition of the rock deposits. As a result of field verification work, the exits of the boundary and the spread of cover sediments were clarified, which served as the first ones to independently identify the SDK of mixtites (Fig. 2). 


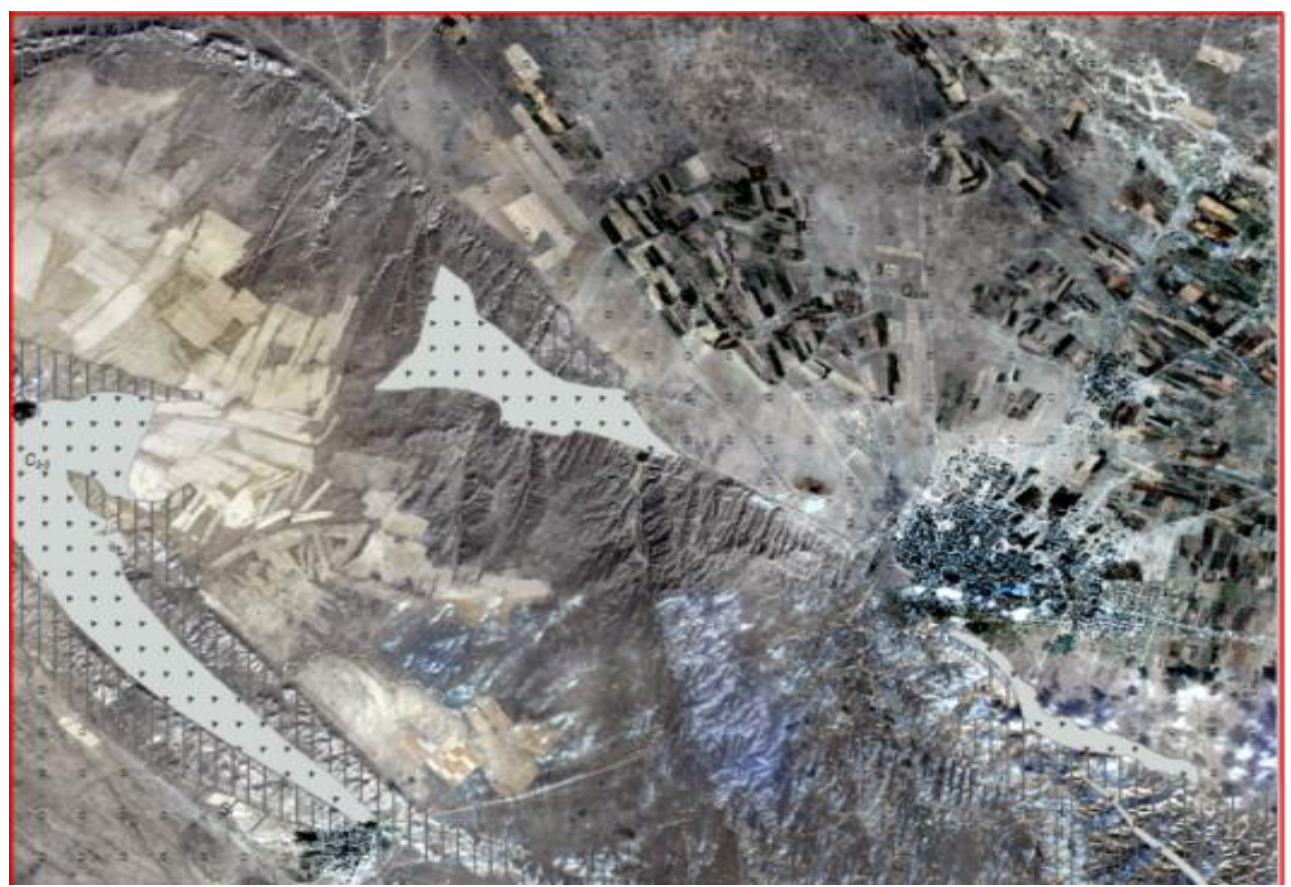

Fig. 2. Mikstite complexes revealed on the territory of the South Nuratau mountains in satellite images.

Improving the quality of regional and detailed exploration work, special geotectonic and geodynamic studies determine the need to study, based on remote sensing materials, the geotectonic, structural-geomorphological and geodynamic (or generally structuralgeodynamic) features of the studied regions in connection with the identification of mineralization zones and belts.

The use of distance materials, which make it possible to perform geological surveys of poorly studied territories at a completely different qualitative level, as well as clarifying the data of traditional geological surveys, testifies to the relevance of developing a new direction of geological surveys, which is proposed to be called a complex cosmogeological survey technique by the totality of the new methods used. Fundamentally new information on the structural plan of the areas studied by geological studies can be obtained either by increasing the detail of the work, or by combining traditional methods using satellite imagery materials. Geological tasks can be solved promptly, which significantly affects the increase in the efficiency of exploration work.

The name and age of the complexes was determined on the basis of a comparison with a geological map, based on its predominant component in the complex. In the work, generalized structurally-decryptable complexes based on satellite imagery materials identified by interpretation are considered [5].

Magmatic complexes:

The intrusive formations, regardless of composition, have similar structural and deciphering features, and in this regard, we divided them into three complexes: 1) granitoid KFOR, 2) gabbroid KFOR, 3) ophiolitic KFOR [5].

Granitoid KFOR. Granitoid intrusive rocks on the territory of the Republic of Uzbekistan are widespread. In space photographs, this complex is painted from gray to dark blue, sometimes with a pinkish tinge. (Fig. 3). 


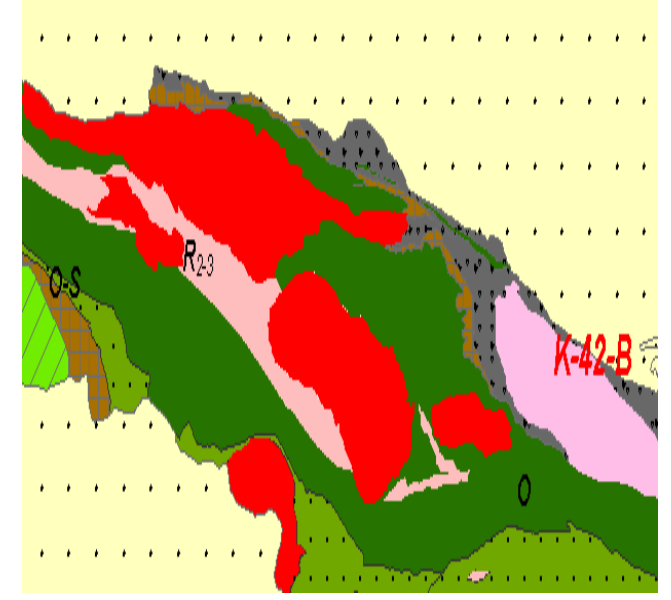

a) Remote base

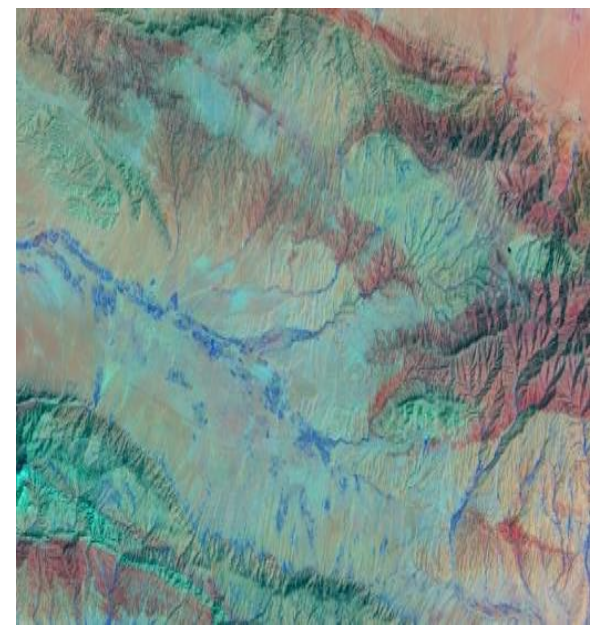

b) A fragment of a space photograph

Fig. 3. Dedicated intrusive structurally decryptable complexes and associated with the remote basis.

For example, intrusive rocks are deciphered by the absence of stratification, by an even photon, and in large-scale photographs sometimes by a net pattern caused by a system of cracks. The erosion system of cracks gives runoff grooves and shallow valleys typical angularity and straightness. Intrusive rocks are highly fortified, therefore, in the sharply continental climate of the Republic of Uzbekistan in areas of high neotectonic activity, they form sharp positive landforms. Under conditions of weak positive movements, softer, smoother shapes such as domes, ridges or almost flat surfaces. The boundaries of intrusive bodies with host rocks are often secant. It should be noted that recently, during geodynamic and metallogenic studies, much attention has been paid to the so-called "mixtite" complexes. Almost simultaneously, L. Shermerhorn introduced the universal term "mixtitis" in 1966, combining all the diversity of chaotic complexes [6,9].

Gabbroid KFOR. The formations of this complex are represented

gabbro, gabbro-diorites, gabbro-amphibolites and are common in the Kyzylkum, South Aral, Nurata and Bukhara-Southern Gissar regions.

In the South Aral region, the intrusions of this complex in the Sultanuvays mountains are represented by the Tebinbulak intrusive massif. In space photographs, the rocks of this complex are colored in greenish tones, from light to dark green.

Ophiolite KFOR. It forms a group of mafic-ultramafic complexes (Sultanuizdag, Bukantau, Nurata-Zirabulak, etc.) located in the Kyzylkumo-Fergana lineament, which can be traced in the latitudinal direction from the Sultanuizdag mountains in the west to the Fergana ridge in the east. The question of the age of ultramafites is considered debatable and varies from Precambrian to the Upper Paleozoic. In space images, the complex is colored from red to dark red with a brownish tint.

Mikstite complexes:

According to the classification of M.G. Leonov (Olistostroma in the structure of folded areas, 1981), the class of mixtites includes several varieties: gravitational landslide landslide mixtites olistostroma; tectonic-gravitational mixtites-tectonized olistostromes; tectonic mixtites - melange, tectonic breccias.

Olistostromic SDK (C2-3). In the Kyzylkum region, the Upper Moscow formations are represented in the lower sedimentary rocks, and in the upper volcanic. Mikstitovy complex in space photographs is painted mainly in dark colors from dark gray to dark blue. 
Melange KFOR (Pz1) is distributed in the Tamdytau mountains in the northern part and in the Bukantau mountains in the south-western part, composed of volcanic rocks, flints, carbonates and shales. It has light yellowish tones, soft relief forms. The rocks of the complex are complicated by discontinuous violations of the northwestern strike, brecciated in places, milonitization, clarification, limonitization are noted.

Stratified complexes:

Metavolcanogenic-carbonate-siliceous SDK (R2-3). This complex is widely developed in the Kyzylkum region: in the Bukantau mountains in the volume of the Kokpatassky suite and in the mountains of Tamdytau. It is composed of epidote-albite-chlorite schists, quartzites, dolomites, limestones and other rocks. On satellite images painted in dark colors.

Shale (crystalline shale) SDK (PR). This complex is exposed in the BaysunPriamudarya district in the eastern part of the Surkhantau mountains. On satellite images painted in greenish-brownish colors.

Metaterrigenic KFOR (O). This complex is represented by metaterrigenous shales with lenticular layers of siliceous rocks, marbled limestones and calcareous dolomites. The photon in the space photograph is expressed in light blue, light brown colors.

Terrigenous KFOR (O-S). Under this index, sediments developed in the BeltauKuraminsky and Nuratinsky districts are shown. The deposits are represented by micaceous-siliceous, shale, clay, mudstone, sandstones and others. The photon is light in the composite image.

Siliceous - carbonate SDK (S2-D1). Deposits passing from Silurian to Devonian are exposed in the Kyzylkum, Nurata, Fergana-Alai and Bukhara-Southern Hissar regions. In the composite image, the photon is light to white [10, 11].

Volcanogenic - carbonate SDK (D). Volcanic formations of the Devonian age are developed in the Beltau-Kuraminsky and Fergana-Alai regions. In space photographs, the rocks are colored from light to white.

Carbonate SDK (D-C). The Devonian and Carboniferous carbonate deposits in the Central Kyzyl Kum region are combined into an undivided Devonian-Carbon structurally decrypted complex. In space photographs, carbonates are colored from light to tan.

Terrigenous-carbonate KFOR (C2). These deposits are developed in the Ustyurt, South Aral, Kyzylkum, Nurata, Fergana-Alai, Bukhara-South Gissar and Baysun-Priamudarya regions. Represented by limestone, dolomites, shales and mudstones. On satellite images, they range from dark green to dark gray, sometimes to black.

Volcanogenic-terrigenous-shale KFOR (C2). This complex is exposed in the eastern part of the Beltau-Kuraminsky belt in Chatkalo-Kuraminsky mountains. On satellite images, it is colored from dark green to dark gray.

Volcanogenic-terrigenous KFOR (R). This complex is common in Chatkalo-Kuramin mountains. In space photographs, it is colored in light colors and occupies a low hypsometric position with the development of soft relief forms.

Terrigenous molasses KFOR (P). This complex is represented by clays, sandstones, mudstones distributed mainly in the northwestern part of the Bukantau mountain uplift. On space photographs it is painted in greenish-pink colors.

Carbonate-terrigenous KFOR (J). The complex is widely developed in the Southern region in the southwestern spurs of the Gissar Range. The color is paler - light gray, sometimes yellowish and green tones predominate.

Terrigenous-carbonate SDK $(\mathrm{K})$. This complex is composed of sediments of shallow water, deltas and, to a large extent, continental formations: sand, sandstone, clay. In space photographs, it is painted in light yellow colors. 
Clay-carbonate SDK (P). This complex is represented mainly in the South Uzbekistan mining region and within the Ferghana Valley, while in other regions of Uzbekistan it is noted in insignificant volumes. On space photographs it is painted in light pink tones.

Sandy-clay SDK (N1-2). This complex is composed of continental deposits and is clearly divided into red and brown parts. In composite images, it appears as dark purple, ovals, and stripes elongated in a northwest direction.

Aeolian KFOR (N-Q). The complex is widely developed in the flat part of the territory of Uzbekistan, in the Aral Sea region and in Kyzylkum. It is emphasized on satellite images by smooth surfaces of light color and has a negative effect on the degree of geological decipherability of the Paleozoic KFOR. The development of KFOR involves a gentle immersion of the foundation under the platform cover.

Alluvial - proluvial KFOR (QIII-IV). KFOR is developed along river valleys and their large tributaries; it composes beds. Dark photon in panchromatic images emphasizes the water content of SDK, and green - in composite images, the development of vegetation [5, $10]$.

When isolating space-structural elements based on structural interpretation of remote sensing materials, the main attention is paid to the analysis of the nature of distribution, distribution and manifestation of elements and relief components, as well as the selection of the optimal scale of remote sensing materials, which allows recording changes in the forms of formation and the material composition of geological and structural objects [7]. It should be noted that the identification of geological structures based on structurally decryptable complexes and individual photometric characteristics of the images are associated with specific geological formations, genetic types of rocks, strata and discontinuous dislocations. The numerical photometric characteristics of the photogenicity of structurally decryptable complexes are the key to recognizing them by color (tonality, saturation, intensity), structure (linear, point, areal) and pattern (general orientation of the mosaic).

Based on these qualitative characteristics, a systematics of structurally decryptable complexes was compiled, which is reflected in the legends of the new generation cosmogeological maps. It should be emphasized that a significant expansion of the range of tasks to be solved, from simple decryption schemes to compiling a geological basis and constructing slice maps of deep levels in various electromagnetic ranges, made it possible to re-analyze the compiled cosmogeological foundations. Remote sensing materials have become the main information base for a new type of integrated geological survey - in geological mapping, hydrogeological, engineering-geological and geoecological studies [6]. Geological objects are characterized by different spectral characteristics. In some spectral ranges, these objects look more contrasting, in others - less. Therefore, it is very important to correctly determine what remote sensing materials are needed to solve specific geological problems. The variety of geological problems to be solved, as well as the dependence of the spectral characteristics of objects on the season, weather, time of day, etc. do not allow to give strict recommendations on the use of images of certain spectral channels.

\section{Conclusion}

Thus, all the obtained results of decoding the CS and field work - faults, structural decryption complexes, and their boundaries form the basis for creating a remote basis (productive map).

Assessing the role of remote sensing in creating the geological basis, it should be noted that this method, especially in combination with geophysical, geochemical, geomorphological methods, is used to solve all the main problems that geologists face in regional geological work. 
On the basis of satellite imagery materials, the geological structure of the territory is refined, new information about the localization and structure of mineral objects appears, and as a result, on the basis of everything done, the main set of maps is compiled [8].

Thus, the distinguished KFMs, which are large geological bodies that are reflected in remote sensing materials, are the basis of advanced technologies for geological exploration of subsurface resources, forecasting, and potential assessment with the allocation of promising areas of the studied territories for advanced exploration work.

\section{References}

1. O.M. Borisov, A.K. Glukh, Ring structures and lineaments of Central Asia (Fan, T., 1982)

2. E. Barrett, L. Kurtis, Introduction to space geography (Remote sensing methods) (Progress, Moscow, 1979)

3. Y.G. Katz, A.G. Ryabukhin, D.I. Trofimov, Space methods in geology (Moscow State University, Moscow, 1976)

4. Ya.G. Katz, The basics of space geology (Nedra, Moscow, 1988)

5. A.K. Nurkhodjaev, I.S. Togaev, R.Z. Shamsiev, A methodological guide for compiling a cosmogeological map of the Republic of Uzbekistan based on digital space images (State Enterprise "Center for Remote Sensing and GIS Technologies”, T., 2017)

6. A.K. Nurkhodjaev, I.S. Togaev, Geology and mineral resources 4, 22-27 (2018)

7. A.K. Nurkhodjaev, A.R. Asadov, Zh.T. Riskidinov, Geology and mineral resources 4, 9-12 (2015)

8. A.K. Nurkhodjaev, I.S. Togaev, Materials of the scientific-practical conference, Actual problems of geology, geophysics and metallogeny, 258-261 (2017)

9. E.G. Fedorov, R.Kh. Mirkamalov, F.K. Divaev, Geology and mineral resources 3, 3-12 (2016)

10. V.A. Arapov, Stratified and intrusive formations of Uzbekistan (IMR, T., 2000)

11. Stratified and intrusive formations of Kyrgyzstan (1982)

12. A.M. Arifjanov, Sh.B. Akmalov, L.N. Samiev, European science review 3-4, 244-248 (2018) 